\title{
SLG(Single-Line-to-Ground) Fault Location in NUGS(Neutral Un-effectively Grounded System)
}

\author{
Wenhai Zhang ${ }^{1}$, Meimei He ${ }^{2}$, Jie Ren ${ }^{1}$, Yongke Wen ${ }^{1}$, Zheng Zhang ${ }^{1}$, Zhou Pu ${ }^{1}$, Rongjian Zhang ${ }^{1}$ \\ ${ }^{1}$ State Grid Sichuan Maintenance Company, Chengdu, Sichuan Province, China \\ ${ }^{2}$ Sichuan Electric Power Design \& Consulting Co,. Ltd., Chengdu, Sichuan Province, China
}

\begin{abstract}
This paper reviews the SLG(Single-Line-to-Ground) fault location methods in NUGS(Neutral Uneffectively Grounded System), including ungrounded system, resonant grounded system and high-resistance grounded system which are widely used in Northern Europe and China. This type of fault is hard to detect and location because fault current is the sum of capacitance current of the system which is always small(about tens of amperes). The characteristics of SLG fault in NUGS and the fault location methods are introduced in the paper.
\end{abstract}

\section{Introduction}

In medium voltage, $10 \mathrm{kV} \sim 35 \mathrm{kV}$, distribution system in China and Nordic countries are mainly NUGS (Neutral Un-effectively Grounded System). The SLG (single-lineto-ground) fault is the most common fault type in NUGS which is also called earth fault by some scholars. It is reported that about $50-80 \%$ of all faults are of this type[1]. This type of fault is different from the line-to-line fault in NUGS and the SLG fault in neutral effective grounded system, the load is not affected by the fault and the fault current is always tens of Amperes which is determined by the capacitive charging current of the system. But the healthy phases' voltage would arise to line-to-line voltage which may cause insulation breakdown and lead to fault expands. The SLG fault may lead to the fire hazard and electric shock. So it is necessary to locate the SLG fault as soon as possible, then isolate it and repair such a fault.

Research on SLG fault location has been conducted for decades. There are many methods have been proposed and can be divided into single measurement based and multiple measurements based, steady signal based and transient signal based, time domain based and frequency based, and so on. However, there is no one could solve the problem very well for many reasons, especially the small fault current and complex system structure. All the methods will be introduced in the paper.

\section{The Characteristics of SLG Fault and Problem Definition}

The typical SLG fault model in NUGS can be depicted as in Fig 1. The system is neutral ungrounded system when breaker $\mathrm{K}$ is open, and it is resonant grounded system when $\mathrm{K}$ is closed. Considering the fault resistance $R_{f}$ and fault distance $\mathrm{D}$ is zero, the fault phase voltage will drop to zero and two healthy phase to ground voltages will increase to times of phase voltage. There is no large fault current for the fault path is high impedance. Fault current If is the sum of all line to ground capacitive current.

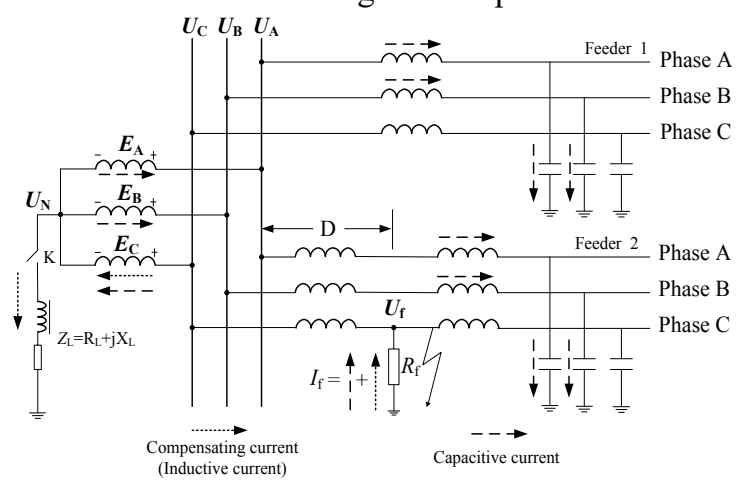

Figure 1. The SLG fault model in neutral ungrounded and resonant grounded system

The transient is obvious when SLG fault happened because large number of energy-storage elements(inductance and capacitance) contained in the system which is introduced in [2] in detail. It has larger amplitude than the steady state fault current. The typical three phase voltage and three phase current waveforms of fault feeder are shown in Fig. 2. When a SLG fault happens, three different components can be distinguished in the transient signal[3]. The discharge transient is initiated when the voltage of the faulty phase falls and the charge stored in its earth capacitances is removed. Because of the voltage rise of the two sound phases, another component, called charge transient, is created. The interline compensating components equalize the voltages of parallel lines at their substation terminals. In compensated networks there is, in addition, a decaying DC-transient of the suppression coil circuit. This component is usually at its highest, when the fault takes 
place close to voltage zero. If the coil is saturated, the current may also include harmonics.

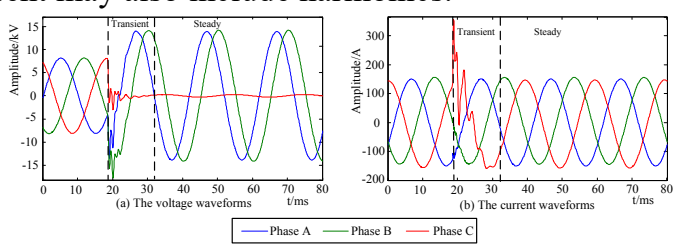

Figure 2 The typical waveforms of SLG fault in NUGS(fault in phase C)

\section{Review of SLG Fault Location Methods in NUGS}

\subsection{The Classification of the Methods}

In the past two decades, many algorithms have been proposed to locate the SLG fault in NUGS. Those methods can be divided into many groups (see Fig 3), which are introduced in this chapter respectively. The passive methods utilize the features cause by fault, and the active methods need some other device to produce disturbance for accurate fault location. The passive methods can be subdivided into single-ended methods and multiple measurements methods based on the number of required measurement devices.

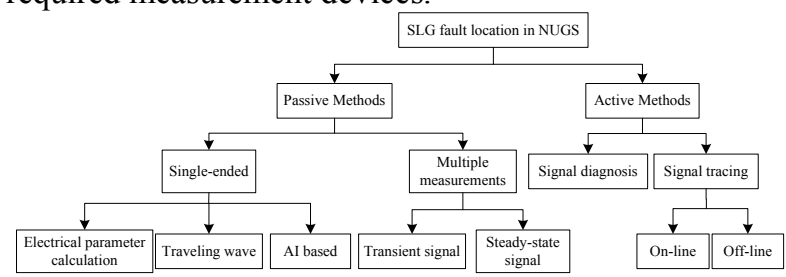

Figure 3. SLG fault location methods in NUGS

\subsection{Electrical Parameter Calculation Based Methods}

\subsubsection{Fundamental Based Methods}

This types method mainly used in effectively grounded system. Because the fault would cause large fault current which can be used for fault distance calculation. It also can be classified into phase analysis based method[4], sequence analysis based method[5].

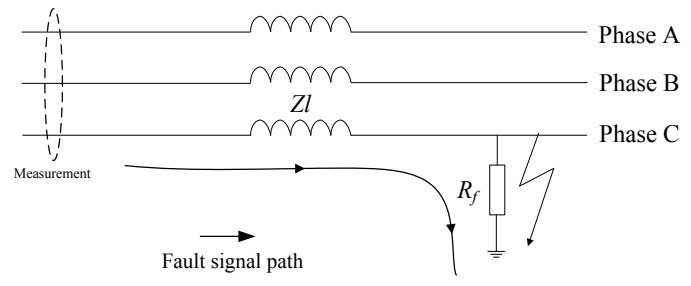

Figure 4. Fault signal path

\subsubsection{Transient Based Methods}

The transient based methods calculate the fault distance by calculating the inductance $\mathrm{L}$ of fault path. There are three methods to calculate the L, including differential equation method, Fourier transform based method and wavelet based method.

\section{(1) Differential equation methods}

The simplified equivalent circuit of fault path is considered as one order R-L circuit. Then the differential equation algorithm calculates the fault distance by numerical solving the differential equation as follows:

$$
u(t)=R \cdot i(t)+L \cdot \frac{d i(t)}{d t}
$$

where $\mathrm{u}(\mathrm{t})$ is the instantaneous voltage; $\mathrm{i}(\mathrm{t})$ is the instantaneous current; $\mathrm{R}$ is the resistance of equivalent $\mathrm{R}$ $\mathrm{L}$ circuit; $\mathrm{L}$ is the inductance of equivalent $\mathrm{R}-\mathrm{L}$ circuit.

The equation can be solved with a numerical integration and the inductance of the fault path can be calculated if three equally spaced pairs of phase currents and voltage samples are available[6].

$$
L=\frac{\Delta t}{2}\left[\frac{\left(i_{k+1}+i_{k}\right)\left(v_{k+2}+v_{k+1}\right)-\left(i_{k+2}+i_{k+1}\right)\left(v_{k+1}+v_{k}\right)}{\left(i_{k+1}+i_{k}\right)\left(i_{k+2}-i_{k+1}\right)-\left(i_{k+2}+i_{k+1}\right)\left(i_{k+1}-i_{k}\right)}\right]
$$

\section{(2) Fourier transform based methods}

In ref[7], a method using the Fourier-transform to calculated the line impedance in frequency domain. The reactance of the faulty line length is obtained directly as the imaginary part of the impedance calculated from the corresponding frequency spectrum components of the voltage and current. Ref[8] use this type method in the cable fault location. But the high frequency signal contained in transient signal is an exponential decaying signal which could cause error using FFT analysis.

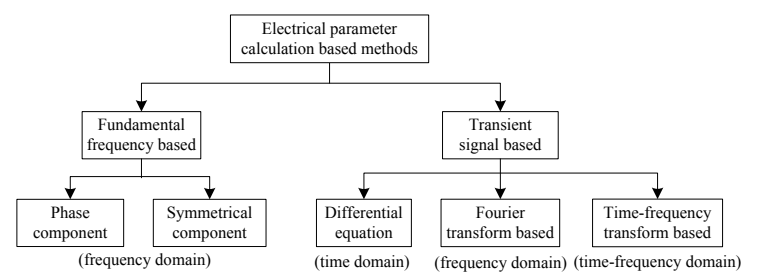

Figure 5. Electrical parameter calculation based methods

\section{(3) Time-frequency transform based methods}

This type of method uses time-frequency transform to extract transient voltage and current to calculate the line impedance. It is based on one specified damped exponential signal for electrical parameter calculation. The wavelet transform is the typical method to extract time variant signal. Ref[9] use continuous wavelet transform to extract the specified signal to calculate fault path inductance.

$$
L=\frac{1}{\omega} \operatorname{imag}\left[\frac{U_{w}(k \Delta t, f)}{I_{w}(k \Delta t, f)}\right]
$$

Where $\omega$ is angular frequency; L is inductance of fault path; Uw and Iw are the wavelet coefficient of voltage and frequency separately; $f$ is frequency for the distance calculation.

The electrical parameter calculation based methods estimate the fault distance by calculating the inductance of transmission line from substation to fault position. These 
methods are mainly single ended, and can be divided into fundamental signal based and transient signal based as shown in Fig 5. The fault distance equation can be formulated in time domain and frequency domain.

\subsection{Traveling Wave Based Methods}

This type of method is not affected by fault type, because it is not based on the fault current analysis. Traveling waves(also called surges) on power lines arise from a number of causes, of which the most common are faults, switching operations, and lighting. Surges on overhead power lines travel at the speed of light, approximately $3 \times 10^{8} \mathrm{~m} / \mathrm{sec}$, and consist of a voltage wave and a current wave related through the surge impedance of the line[10]. There are two types of traveling wave based methods, first one utilizes the traveling wave propagates time from fault point to substation combine with traveling wave speed for calculation; another one is based on the traveling wave frequency for calculation.

\subsubsection{Time-distance based methods}

The traditional traveling wave based method in distribution system is the single-ended method using the time difference between the first arrival of an incident traveling wave generated by a fault and corresponding reflected wave reflected from point. We nominated this type method time-distance based traveling wave method in this paper. The principle of the method is shown in Fig 6. Knowing this time delay and traveling wave velocity the place of fault is determined. In three-phase networks, the traveling waves are mutually coupled which means a single traveling wave velocity does not exist. Therefore, the phase domain signals are first decomposed into their modal components by means of the modal transformation matrices and each node is treated separately.

Considering the fault is detected at end S, the singleended fault distance calculation is as follows[11]:

$$
D=\frac{v \cdot\left(t_{s 3}-t_{s 1}\right)}{2}
$$

where $\mathrm{D}$ is fault distance, $\mathrm{v}$ is traveling wave velocity; t0 is fault time, then the fault generate arrives at end $\mathrm{S}$ at time $t_{s l}$, and $t_{s 3}$ is the time traveling wave reflect from fault point. It is necessary to distinguish between the reflected wave from the fault point and that from the remote bus-bar.

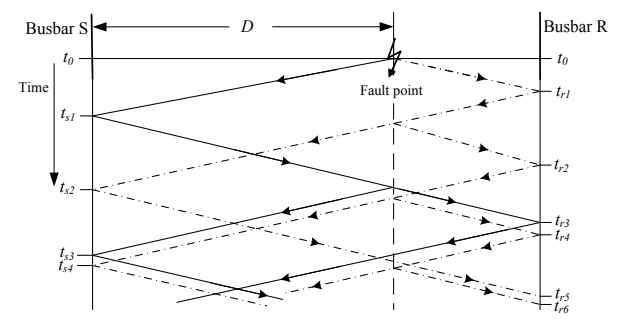

Figure 6 The reflection of traveling wave in the system

In this method, high-frequency voltage signals in the frequency range of 1 to $10 \mathrm{MHz}$ are captured for fault location purpose[11]. In order to apply the method in three-phase systems, modal transform are used to extract the aerial mode and ground mode signals. It has been proven that the fault-generated high-frequency transient signal is not affected by the variation of fault type or fault path impedance.

The most critical issue in these methods is detecting and extracting desired part of the signal, which indicates the traveling of the waves. There are many methods have been proposed to identify the reflected wave, including cross-correlation[12], wavelet transform and so on.

\subsubsection{Frequency-distance based methods}

Another type of traveling wave based method is emerged in recent years which utilize the relationship between specific paths in the network and traveling wave frequency. Fault-originated traveling waves propagate along the network and reflect at line terminations, junctions between feeders, and the fault location. The characteristic frequency of the path is determined by the length and structure of the system[13].

Ref[14] introduced the relationship between characteristic frequency, traveling wave speed and signal path. Assuming the network topology and the traveling wave speeds of the various propagation modes are known, frequency of mode through path can be evaluated a priori as:

$$
f_{p, i}=\frac{v_{i}}{n_{p} L_{p}}
$$

where $v_{i}$ is the traveling speed of the ith propagation mode, $L_{p}$ is the length of the pth path and $n_{p}(\in \mathrm{N})$ is the number of times needed for a given traveling wave to propagates along path $\mathrm{p}$ before attain again the same polarity. $\mathrm{p}-1$ values are used to identify the faulted section and the remaining one to identify the fault distance between observation point $\mathrm{m}$ and the fault location. The method of associating a characteristic frequency to each path was introduced in the paper.

\subsection{Multiple Measurement Based Methods}

The multiple measurements based methods is a kind of fault section identification method. The fault section is identified by comparing the current or some other features measured along the distribution line. It can be recognized as expansion of fault feeder identification. The methods can be subdivided into transient based and steady state based. Most of these methods are on-line fault location, and there are some requirements for the measurement device, such as sample frequency, synchronization, telecommunication and so on. The comparison of the different methods are shown in Table 1.

\subsection{Signal Tracing Based Method}

This method is a typical active method which locates the fault by tracing the injected signal path by signal detector, including handheld detector and fixed detector along the line. The signal injection methods have been used for the fault detection and fault feeder identification. The fault 
location can be recognized as the expansion of these methods which need to trace the injected signal path.

The injected signal would pass through the fault point and back to the injected point through the ground. It means that the fault is in the downstream of measure point if the injected signal can be detected in this point.

The requirements for the injected signal are that: 1) it is distinguishable; 2) the signal and its source do not adversely affect the performance of the equipment. There are three typical research team have used this type of method as shown in Fig. 7. Then the three methods and modified would be introduced separately.

\subsection{Signal Diagnosis Methods}

The signal diagnosis algorithm is based on transfer functions and frequency spectrum analysis, using the response of the applied impulse in the frequency domain to construct criteria for the fault location[27]. It is a type of active method which needs signal injection. The method has been proposed for several years but it is verified just by the computer simulation and hasn't been used in field test.

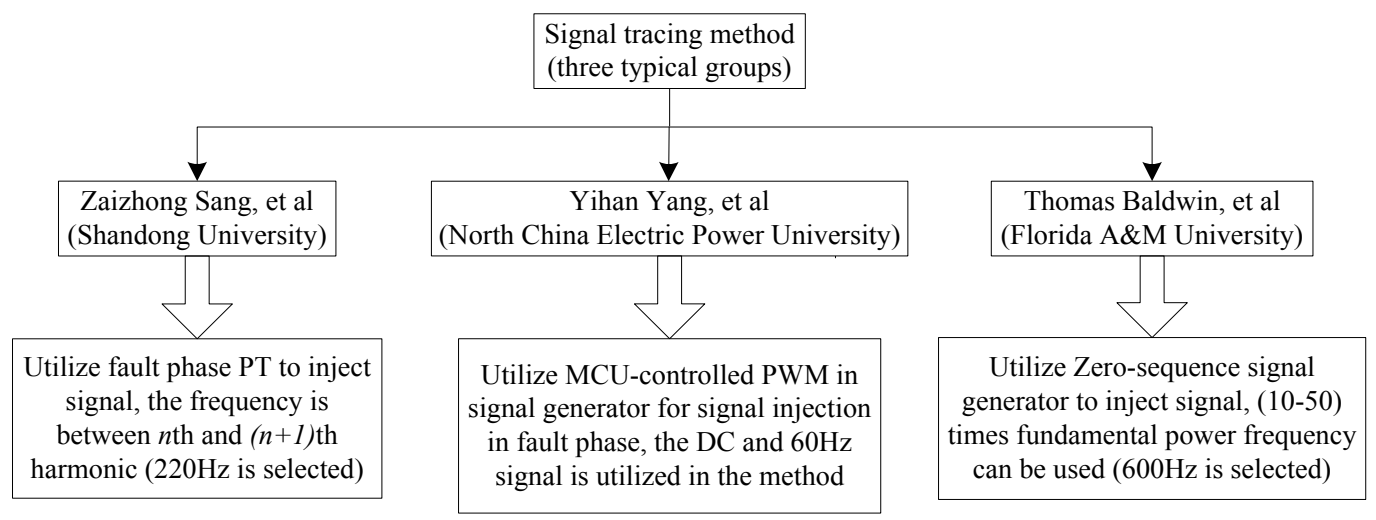

Figure 7. The comparison of three typical signal tracing based methods

Table 1. The comparison of the different multiple measurements based method

\begin{tabular}{|c|c|c|c|c|}
\hline \multicolumn{2}{|r|}{ Features } & \multirow{2}{*}{$\begin{array}{l}\text { Ref. } \\
14\end{array}$} & \multirow{2}{*}{$\begin{array}{c}\text { Measurements } \\
I_{0} \text { along the line and magnetic } \\
\text { field detection }\end{array}$} & General principle \\
\hline \multirow{7}{*}{$\begin{array}{l}\text { Steady state } \\
\text { based } \\
\text { methods } \\
\text { (using } \\
\text { fundamental } \\
\text { signal) }\end{array}$} & Amplitude of $I_{0}$ & & & $\begin{array}{l}\text { Upload the } \mathrm{I}_{0} \text { along the line to primary substation for fault section } \\
\text { identification, then detect the fault position by detecting the magnetic } \\
\text { field of fundamental frequency signals }\end{array}$ \\
\hline & $\begin{array}{l}\text { The phase difference } \\
\text { between } U_{0} \text { of bus and } I_{0} \\
\text { of the line }\end{array}$ & 15 & $U_{0}$ of bus and $I_{0}$ along the line & $\begin{array}{l}\text { The voltage and current need to be synchronous measurement. Measures } \\
\text { current using portable current measurement based on magnetic field } \\
\text { detection. }\end{array}$ \\
\hline & $\begin{array}{l}\text { The phase difference } \\
\text { between the } I_{0} \text { of two } \\
\text { adjacent nodes }\end{array}$ & 16 & $I_{0}$ along the line & $\begin{array}{l}\text { The fault section is identified based on the absolute different between the } \\
\text { approximate zero-sequence angles of two adjacent nodes. }\end{array}$ \\
\hline & $\begin{array}{l}\text { Direction of zero } \\
\text { sequence power }\end{array}$ & 17 & $U_{0}$ of bus and $I_{0}$ along the line & $\begin{array}{l}\text { Measure the zero sequence current using magnetic detection, use the } \\
\text { synchronized zero sequence voltage of bus to calculate zero sequence } \\
\text { power }\end{array}$ \\
\hline & $5^{\text {th }}$ harmonic & 18 & electric and magnetic field & $\begin{array}{l}\text { Detect the fault point by the portable and non-contact voltage and current } \\
\text { measurement, the amplitude and phase are considered simultaneously }\end{array}$ \\
\hline & Composite method & 19 & $U_{0}$ of bus and $I_{0}$ along the line & $\begin{array}{l}\text { Combine the magnitude and phase comparison implemented by using the } \\
\text { mobile zero sequence CT and wide area phase measurement }\end{array}$ \\
\hline & The increment of $I_{0}$ & 20 & $U_{0}$ of bus and $I_{0}$ along the line & Detect zero sequence current variation after adjust Peterson coil \\
\hline \multirow{6}{*}{$\begin{array}{l}\text { Transient } \\
\text { signal based } \\
\text { methods }\end{array}$} & $\begin{array}{l}\text { Transient reactive power } \\
\text { direction }\end{array}$ & 21 & $\begin{array}{l}\text { The electric field and magnetic } \\
\text { field }\end{array}$ & $\begin{array}{l}\text { The reactive power direction calculated using the transient signals in the } \\
\text { selected frequency band is used for the fault section identification }\end{array}$ \\
\hline & $\begin{array}{l}\text { Polarity of a specific } \\
\text { frequency band power }\end{array}$ & 22 & $\begin{array}{l}\text { Residual voltage and residual } \\
\text { current }\end{array}$ & $\begin{array}{l}\text { Fault section identification is based on the polarity of a specific } \\
\text { frequency band power computed by multiplying the DWT detail } \\
\text { coefficient }\end{array}$ \\
\hline & $\begin{array}{l}\text { The waveform similarity } \\
\text { of two adjacent nodes }\end{array}$ & 23 & The waveform of $I_{0}$ & $\begin{array}{l}\text { Calculate the correlation of transient zero current for fault section } \\
\text { identification. }\end{array}$ \\
\hline & $\begin{array}{l}\text { The relationship between } \\
\text { phase current and } I_{0}\end{array}$ & 24 & Three phase currents & Utilize the difference between phase current and zero sequence current \\
\hline & $\begin{array}{l}\text { The product of transient } \\
\text { line-to-line voltage and } \\
\qquad I_{0}\end{array}$ & 25 & $\begin{array}{l}\text { Line-to-line voltage and } I_{0} \text { along } \\
\text { the line }\end{array}$ & $\begin{array}{l}\text { The product of transient line-to-line voltage after Hilbert transformation } \\
\text { and transient zero-mode current is defined as the parameter of fault } \\
\text { direction. }\end{array}$ \\
\hline & Composite & 26 & $\begin{array}{l}\text { Line-to-line voltage and } I_{0} \text { along } \\
\text { the line }\end{array}$ & $\begin{array}{l}\text { Upload the fault data by FTU, and identified the fault section combine } \\
\text { transient reactive power direction method and transient current similarity } \\
\text { location method }\end{array}$ \\
\hline
\end{tabular}




\subsection{Al Based Methods}

The AI(artificial intelligence) based method is proposed with the development of computer and power system simulation. It is also used by some scholars for the SLG fault location, including $\mathrm{ANN}$ (artificial neural network) based method proposed by [28] and Fuzzy neural network based method proposed by [29]. All the fault features including transient and steady fault features could be used in the type methods. But it needs training and retraining when the structure of the system changed. The large number of actual fault data or simulation results is need for the training.

\section{Conclusion}

Although there are many methods have been proposed, there is no one is practical and low-cost which can be spreaded based on investigation. There are some methods have been in field test, such as transient signal based parameter calculation methods, multi-measurements based methods and signal injection methods. But the transient signal based parameter calculation method is low robustness for the amplitude of transient signal is affected by fault resistance and fault inception angle; multimeasurements based methods are high-investigation maintenance workload and the reliability is also affected by fault resistance. The signal injection based methods are time consuming and the operation is complex. Based on the features of SLG fault and the existing location methods, some advices are proposed as follows:

(1) Considering the complexity of distribution system, increase accurate measurement points in the system for accurate calculation is important;

(2) The signal injection based methods are the most reliable, but most of them are off-line and time consuming. The idea of active method can be considered to enhance the reliability of location for the SLG fault features are too weak;

(3)There are big differences between the developments of distribution systems; the measurements in the systems are different. Then the different fault location methods should be proposed to adapt the measurement condition of system.

\section{References}

1. Seppo Hanninen, and Matti Lehtonen. "Characteristics of earth faults in electrical distribution networks with high impedance earthing." Electric Power Systems Research 44.3 (1998): 155-161.

2. Druml, Gernot, Andreas Kugi, and Olaf Seifert. "A new directional transient relay for high ohmic earth faults." CIRED 17th International Conference on Electricity Distribution, Barcelona, Spain. 2003.

3. Seppo Hanninen. Single phase earth faults in high impedance grounded networks: characteristics, indication and location. VTT Technical Research Centre of Finland, 2001.

4. Seppo Hanninen, and Matti Lehtonen. "Earth fault distance computation with fundamental frequency signals based on measurements in substation supply bay." VTT TIEDOTTEITA (2002).

5. Soon-Ryul Nam, et al. "Ground-fault location algorithm for ungrounded radial distribution systems." Electrical Engineering 89.6 (2007): 503508.

6. Hanninen, S., et al. "Comparison of wavelet and differential equation algorithms in earth fault distance computation." Proceedings of Conference on Power System Computation, Norway. 1999.

7. Igel, M., H - J. Koglin, and P. Schegner. "New algorithms for earthfault distance protection in insulated and compensated networks." European Transactions on Electrical Power 1.5 (1991): 253259.

8. Ke Jia, David Thomas, and Mark Sumner. "A new single-ended fault-location scheme for utilization in an integrated power system." Power Delivery, IEEE Transactions on 28.1 (2013): 38-46.

9. Imriš, Peter. Transient based earth fault location in $110 \mathrm{kV}$ subtransmission networks. Helsinki University of Technology, 2006.

10. Zhang, Fan, et al. "New Algorithm Based on Traveling Wave for Location of Single Phase to Ground Fault in Tree Type Distribution Network." Zhongguo Dianji Gongcheng Xuebao(Proceedings of the Chinese Society of Electrical Engineering). Vol. 27. No. 28. 2007.

11. YU, Sheng-nan, Hai BAO, and Yi-han YANG. "Practicalization of Fault Location in Distribution Lines [J]." Proceedings of the CSEE 28 (2008): 016.

12. Borghetti, Alberto, et al. "On the use of continuouswavelet transform for fault location in distribution power systems." International Journal of Electrical Power \& Energy Systems 28.9 (2006): 608-617.

13. Ye, Lei, et al. "An improved fault-location method for distribution system using wavelets and support vector regression." International Journal of Electrical Power \& Energy Systems 55 (2014): 467-472.

14. ZHANG, Li, et al. "Distribution Network Fault Location Based on the Zero Sequence Current and Magnetic Field Detection Spot." Automation of Electric Power Systems 14 (2008): 017.

15. ZHANG, Li, et al. "Method of mobile phasecomparison for fault location of distribution network." Proceedings of the CSEE 7 (2009): 015.

16. Nam, Soon-Ryul, et al. "Single line-to-ground fault location based on unsynchronized phasors in automated ungrounded distribution systems."Electric Power Systems Research 86 (2012): 151-157.

17. Li, Zhang, et al. "Online fault location of neutral point ungrounded distribution network based on zero-sequence power direction." Automation of Electric Power Systems 32.17 (2008): 79-82. 
18. LI, Meng-qiu, et al. "A new approach on detecting the single-to ground fault location on power system with neutral unearthed [J]." Proceedings of the Csee10 (2001)

19. Yang Yihan, et al. " Research on fault location online for neutral point ungrounded system" Journal of North China Electric University, 35.6 (2008): 1-6.

20. Wang, Yumei, Hao Guo, and Shengda Hui. "Fault Location Approach for Resonant Grounded System Based on Remnant Current Increment Method."Automation of Electric Power Systems 2 (2011): 015.

21. Sun, Bo, et al. "Single phase to ground fault section location based on transient signals in non-solidly earthed network." Autom Electr Power Syst 32.3 (2008): 52-55.

22. Elkalashy, Nagy I., et al. "DWT-based detection and transient power direction-based location of highimpedance faults due to leaning trees in unearthed MV networks." Power Delivery, IEEE Transactions on 23.1 (2008): 94-101.

23. Ma, Shicong, et al. "An earth fault locating method in feeder automation system by examining correlation of transient zero mode currents." Autom Electric Power Syst 32.7 (2008): 48-52.
24. Sun, Bo, et al. "Earth fault location based on transient phase current in non-solidly earthed network." Power System Protection and Control 40.18 (2012): 69-74.

25. Linli, ZHANG., et al. "Transient Fault Locating Method Based on Line Voltage and Zero-mode Current in Non-solidly Earthed Network." Proceedings of CSEE 32.013 (2012): I0015-I0015.

26. Xue Yongduan, et al. "Small-current grounding fault location based on transient signals of distribution automation system" Electric Power Automation Equipment, 33.12(2013)

27. Yi Guiye, Yang Xuechang, Wu Zhensheng. "Transfer function algorithm for locating ground faults in power distribution networks" J Tsinghua Univ(Sci \& Tech), 2000, 40(7): 31-34.

28. Hanninen, S., and M. Lehtonen. "Earth fault distance computation with artificial neural network trained by neutral voltage transients." Power Engineering Society Summer Meeting, 2001. Vol. 2. IEEE, 2001.

29. Chunju, Fan, et al. "Application of wavelet fuzzy neural network in locating single line to ground fault (SLG) in distribution lines." International Journal of Electrical Power \& Energy Systems 29.6 (2007): 497-503. 